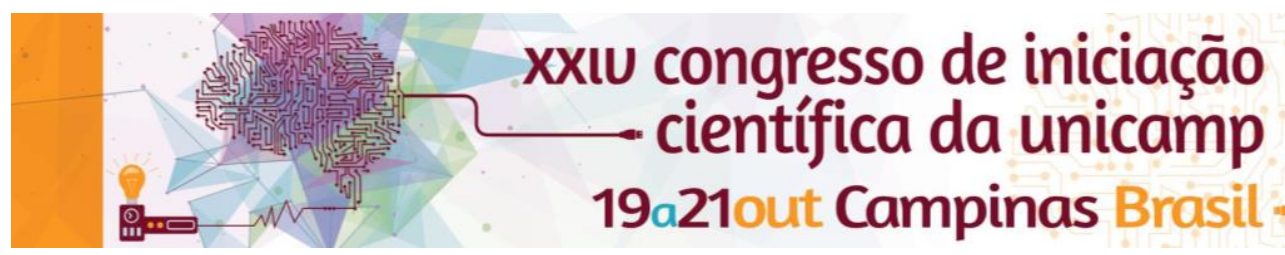

\title{
Implementação de módulo de representação de heatmaps reordenáveis no Google Charts
}

\author{
Clara Anna Rosa Dias de Miranda*
}

\section{Resumo}

Matrizes reordenáveis são estruturas subjacentes a diferentes tipos de visualização de dados, como por exemplo heatmaps. Diferentes algoritmos possibilitam uma permutação automática de seus elementos para prover um melhor entendimento visual, procurando agrupar linhas e colunas similares e evidenciar padrões. Adicionalmente, usuários podem fazer reordenações manuais nessas matrizes. Este trabalho visa a implementação de módulo de representação de heatmaps baseados em matrizes reordenáveis na biblioteca Google Charts. Com este desenvolvimento e sua publicação, espera-se disseminar o uso desta representação visual e de seus algoritmos.

\section{Palavras-chave}

Heatmaps Reordenáveis, Google Charts, Visualização de Informação..

\section{Introdução}

Matrizes reordenáveis são estruturas subjacentes a diferentes tipos de visualização de dados, como por exemplo heatmaps. Diferentes algoritmos possibilitam uma permutação automática de seus elementos para prover um melhor entendimento visual, procurando agrupar linhas e colunas similares e evidenciar padrões. Adicionalmente, usuários podem fazer reordenações manuais nessas matrizes.

O Google Charts foi escolhido como plataforma de desenvolvimento por ser uma ferramenta muito dinâmica, com amplas aplicações e em constante evolução, tornando possível futuras atualizações e implementação de novos módulos e algoritmos de ordenação, além de incentivar muito a criação de módulos personalizados.

\section{Resultados e Discussão}

Para a implantação desse projeto, em sua fase de análise, foram estudadas e comparadas diversas ferramentas de visualização de informação. As principais ferramentas analisadas foram:

-Bioheatmaps: um módulo personalizado do Google Charts feito especificamente para gerar heatmaps.

-D3: Biblioteca Javascript para manipulação de documentos baseados em dados, que já possuí alguns algoritmos de ordenação nativos.

- Reorder.JS: Biblioteca Javascript, baseada na D3, para criação e reordenação de heatmaps.

-ViMaR: Software específico para visualização de matrizes reordenáveis.

Também foram considerados na análise, métodos os métodos de inserção de dados, interações e personalizações de visualização suportados por cada ferramenta, para que a ferramenta a ser desenvolvida preenchesse as lacunas deixadas pelas outras e assim pudesse ser utilizada como forma de divulgação e popularização do uso de Matrizes Reordenáveis para visualização de informação.

\section{Conclusões}

O projeto foi interrompido durante sua fase de implementação. No entanto a fase de planejamento e levantamento de requisitos e características desejáveis apontou que a Com base nas análises realizadas $A$ ferramenta em desenvolvimento seria baseada em três bibliotecas Javascript: Bioheatmaps, D3 e Reorder.JS. Sendo a primeira já presente no Google Charts. Os método de inserção de dados mais viáveis seriam via código Javascript, tabelas (HTML) e JSON.

Embora não tenha sido possível concluir a ferramenta na forma de Iniciação Tecnológica, muito já foi feito e estudado, tornando muito possível e provável que sua conclusão venha por forma de Trabalho de Conclusão de Curso.

\section{Agradecimentos}

Aproveito o espaço para agradecer ao meu orientador, Celmar Guimarães, pela chance e por todo apoio ao projeto.

Agradeço também à república Rota Alternativa que me abriga desde que cheguei chegada a Limeira e me proporciona conforto de ter um lar e uma família, longe de minha cidade natal.

Visualization: BioHeatMap - A Heatmap for Gene Expression and Other Data - Disponível em:

$<$ http://informatics.systemsbiology.net/visualizations/heatmap/bioheatmap. html>. Acessado em:12/02/2016.

D3.js - Data-Driven Documents - Disponível em < http://d3js.org/>. Acessado em: 12/02/2016.

Jean-Daniel Fekete. Reorder.js: A JavaScript Library to Reorder Tables and Networks. IEEE VIS 2015, Oct 2015, Chicago, United States. 2015, <http://ieeevis.org>. <hal01214274>

ADRIANI MARTINI FONSECA. Representação de Matrizes Reordenáveis por meio de um kit de ferramentas de Visualização de Informação (2010) Trabalho de Graduação Interdisciplinar - Faculdade de Tecnologia, Universidade de Campinas - Limeira. 